\title{
Impaired Recent, but Preserved Remote, Autobiographical Memory in Pediatric Brain Tumor Patients
}

\author{
@Melanie J. Sekeres, ${ }^{1,2,9,10,11}$ Lily Riggs, ${ }^{1}$ Alexandra Decker, ${ }^{1}$ Cynthia B. de Medeiros, ${ }^{1}$ Agnes Bacopulos, ${ }^{9}$ \\ Jovanka Skocic, ${ }^{1}$ Kamila Szulc-Lerch, ${ }^{1}$ Eric Bouffet, ${ }^{1}$ B Brian Levine, ${ }^{2,3,9}$ Cheryl L. Grady, ${ }^{2,6,9}$ Donald J. Mabbott, ${ }^{1,2}$ \\ Sheena A. Josselyn, ${ }^{1,2,4,5,7}$ and $\odot$ Paul W. Frankland ${ }^{1,2,4,5,8}$ \\ ${ }^{1}$ Program in Neurosciences and Mental Health, The Hospital for Sick Children, Toronto, Ontario M5G 1X8, Canada, ${ }^{2}$ Department of Psychology, \\ ${ }^{3}$ Department of Medicine (Neurology), ${ }^{4}$ Institute of Medical Science, ${ }^{5}$ Department of Physiology, ${ }^{6}$ Department of Psychiatry, University of Toronto, \\ Toronto, Ontario M5T 1R8, Canada, ${ }^{7}$ Brain, Mind \& Consciousness Program, Canadian Institute for Advanced Research, Toronto, Ontario M5G 1M, \\ Canada, ${ }^{8}$ Child \& Brain Development Program, Canadian Institute for Advanced Research, Toronto, Ontario M5G 1M1, Canada, ${ }^{9}$ Rotman Research \\ Institute, Baycrest, Toronto, Ontario M6A 2E1, Canada, ${ }^{10}$ Department of Psychology and Neuroscience, and ${ }^{11}$ Department of Biology, Baylor University, \\ Waco, Texas 76798
}

\begin{abstract}
Medulloblastomas, the most common malignant brain tumor in children, are typically treated with radiotherapy. Refinement of this treatment has greatly improved survival rates in this patient population. However, radiotherapy also profoundly affects the developing brain and is associated with reduced hippocampal volume and blunted hippocampal neurogenesis. Such hippocampal (as well as extrahippocampal) abnormalities likely contribute to cognitive impairments in this population. While several aspects of memory have been examined in this population, the impact of radiotherapy on autobiographical memory has not previously been evaluated. Here we evaluated autobiographical memory in male and female patients who received radiotherapy for posterior fossa tumors (PFTs), including medulloblastoma, during childhood. Using the Children's Autobiographical Interview, we retrospectively assessed episodic and nonepisodic details for events that either preceded (i.e., remote) or followed (i.e., recent) treatment. For post-treatment events, PFT patients reported fewer episodic details compared with control subjects. For pretreatment events, PFT patients reported equivalent episodic details compared with control subjects. In a range of conditions associated with reduced hippocampal volume (including medial temporal lobe amnesia, mild cognitive impairment, Alzheimer's disease, temporal lobe epilepsy, transient epileptic amnesia, frontal temporal dementia, traumatic brain injury, encephalitis, and aging), loss of episodic details (even in remote memories) accompanies hippocampal volume loss. It is therefore surprising that pretreatment episodic memories in PFT patients with reduced hippocampal volume are retained. We discuss these findings in light of the anterograde and retrograde impact on memory of experimentally suppressing hippocampal neurogenesis in rodents.
\end{abstract}

Key words: autobiographical memory; episodic memory; hippocampus; medulloblastoma; neurogenesis; radiotherapy

\section{Significance Statement}

Pediatric medulloblastoma survivors develop cognitive dysfunction following cranial radiotherapy treatment. We report that radiotherapy treatment impairs the ability to form new autobiographical memories, but spares preoperatively acquired autobiographical memories. Reductions in hippocampal volume and cortical volume in regions of the recollection network appear to contribute to this pattern of preserved preoperative, but impaired postoperative, memory. These findings have significant implications for understanding disrupted mnemonic processing in the medial temporal lobe memory system and in the broader recollection network, which are inadvertently affected by standard treatment methods for medulloblastoma tumors in children.

\section{Introduction}

Medulloblastomas are the most common malignant brain tumor in children (Northcott et al., 2012). While the introduction of cranial radiotherapy in the 1950 s greatly improved survival rates (Ramaswamy et al., 2016), this treatment also profoundly affects the developing brain and impairs cognitive development (Roman 
and Sperduto, 1995). For instance, children treated with radiation for medulloblastomas exhibit reduced white matter and hippocampal volume, and reductions in hippocampal volume have been correlated with memory impairments, assessed using the Children's Memory Scale (CMS; Riggs et al., 2014). Moreover, postmortem immunohistochemical examination of brains from three medulloblastoma patients revealed a 10 -fold reduction in neurogenesis in the hippocampus (Gibson and Monje, 2012), a region where neurogenesis persists into adulthood in humans (Kempermann et al., 2018). These brain abnormalities as well as others associated with radiotherapy may contribute to poorer academic performance (Mabbott et al., 2005) and reduced rates of high school graduation and employment in survivors (Siffert and Allen, 2000; Correa et al., 2004).

Cognitive dysfunction in children receiving cranial radiation for brain tumors has been well characterized and includes deficits in processing speed and attention (Langer et al., 2002; Armstrong et al., 2010; Gibson and Monje, 2012; Scantlebury et al., 2016). While several different aspects of memory function have been examined (e.g., recall and recognition of verbal working memory; Copeland et al., 1999; Reeves et al., 2006; Ehrstedt et al., 2016), autobiographical memory integrity has not previously been characterized in this population. In this study, we therefore retrospectively probed autobiographical memories for a recent event (i.e., within the previous month, and therefore post-treatment) and a remote event (i.e., one that preceded treatment) in patients treated with cranial radiation for posterior fossa tumors (PFTs; medulloblastoma and ependymoma) during childhood.

Autobiographical memory is a form of declarative memory that includes both episodic and semantic components. Episodic components are linked to a unique event (occurring within a specific time and place) and contain precise perceptual and emotional details that allow an individual to mentally re-experience the event (e.g., recollecting a family trip to Disneyland). Semantic components include knowledge about the world and general personal facts (e.g., knowing that Disneyland is in California).

To assess autobiographical memory, we used a modified version of the Autobiographical Interview (AI; Levine et al., 2002), adapted for children [Children's Autobiographical Interview (CAI); Willoughby et al., 2012]. This allowed us to assess retention of both episodic (internal details) and nonepisodic (semantic and other external details) components of recent and remote autobiographical memories. Autobiographical memories, especially the episodic components, are known to rely on medial temporal lobe structures, including the hippocampus and the fornix (the main hippocampal white matter tract), as well as cortical regions composing the recollection network (Addis et al., 2004; Moscovitch et al., 2005; Steinvorth et al., 2005; Svoboda et al., 2006; Hodgetts et al., 2017). The AI is particularly sensitive to detecting retrograde episodic autobiographical impairment in patients with medial temporal lobe damage (Murphy et al., 2008; St-Laurent et al., 2009). Given the relationship between hippocampal integrity and episodic memory, we hypothesized that

Botley, Lyn van Kampen, Kiran Beera, Ruth Weiss, and Tammy Rayner. We thank the two anonymous reviewers for their valuable comments on this manuscript.

The authors declare no competing financial interests.

Correspondence should be addressed to either of the following: Melanie J. Sekeres, Department of Psychology \& Neuroscience, Baylor University, 101 Bagby Avenue,Waco, TX 76706, E-mail:melanie_sekeres@baylor.edu; or Paul W. Frankland, Program in Neurosciences \& Mental Health, Hospital for Sick Children, 686 Bay Street, Toronto, ON M5G 0A4, Canada, E-mail: paul.frankland@sickkids.ca.

DOI:10.1523/JNEUROSCI.1056-18.2018

Copyright $\odot 2018$ the authors $\quad 0270-6474 / 18 / 388252-11 \$ 15.00 / 0$
Table 1. Demographics and clinical details of PFT patients and control participants

\begin{tabular}{|c|c|c|}
\hline Parameter & PFT group $(n=13)$ & Healthy controls $(n=28)$ \\
\hline Sex & 4 females, 9 males & 13 females, 15 males \\
\hline Handedness & 10 right, 3 left & 24 right, 4 left \\
\hline Mean age at test and MRI scan (years) & $13.92(S D, 2.9)$ & $13.14(S D, 3.1)$ \\
\hline Range & $10.7-18.8$ & $7.8-18.0$ \\
\hline Mean maternal education (years)* & $15.36(S D, 2.2)$ & $16.5(S D, 2.5)$ \\
\hline Range & $12.0-18.0$ & $12.0-22.0$ \\
\hline \multicolumn{3}{|l|}{ Diagnosis } \\
\hline Medulloblastoma & 12 & - \\
\hline Ependymoma & 1 & - \\
\hline Mean age at radiation (years) & $6.59(S D, 2.7)$ & - \\
\hline Range & $2.85-11.84$ & - \\
\hline Mean time since radiation (years) & $7.42(4.1)$ & - \\
\hline Range & $1.65-13.87$ & - \\
\hline \multicolumn{3}{|l|}{ Surgical outcome } \\
\hline$>90 \%$ tumor resected & 9 & - \\
\hline Between 50 and $90 \%$ resection & 3 & - \\
\hline Biopsy & 1 & - \\
\hline \multicolumn{3}{|l|}{ Presence of hydrocephalus } \\
\hline No hydrocephalus & 6 & - \\
\hline Hydrocephalus with treatment & 7 & - \\
\hline Presence of posterior fossa mutism & 4 & - \\
\hline \multicolumn{3}{|l|}{ Average radiation dose and type (Gy) } \\
\hline Head/spine + posterior fossa boost & $5.8(S D, 0.9)$ & - \\
\hline Range head/spine & $2.43-3.6$ & - \\
\hline Range posterior fossa & $1.8-5.58$ & - \\
\hline Head/spine + tumor bed & $5.5(S D, 0.09)$ & - \\
\hline Range head/spine & $2.43-3.6$ & - \\
\hline Range tumor bed & $1.8-3.24$ & - \\
\hline
\end{tabular}

*Maternal education was not available for one control and two PFT patients. For a list of questions asked to each participant during the 'specific probe' stage of the CAI (see Table 1-1, available at https://doi.org/10.1523/ JNEUROSCI.1056-18.2018.t1-1)

differences in autobiographical memory quality between patients and controls would especially emerge in reporting of episodic details in the CAI.

\section{Materials and Methods}

Participants. Participants were 13 survivors of PFTs $(n=12$ medulloblastoma, 1 ependymoma) who had been treated with surgical resection of the tumor, followed by craniospinal radiotherapy and chemotherapy $\geq 1$ year before study participation (Table 1). Chemotherapy treatment varied according to each patient's treatment protocol and included some combination of the following agents: carboplatin, ifosfamide, etopiside, vincristine, cisplatin, cyclophosphamide, lomustine, vinblastine, methotrexate, amifostine, and/or temozolomide. Nine male and four female patients were recruited through the brain tumor program at the Hospital for Sick Children as part of a larger clinical research study (Decker et al., 2017). Nine age-matched healthy control children (five female) were also recruited through this clinical study. All participants had complete CAI, standardized memory testing, and neuroimaging data. An additional 19 age-matched healthy controls (eight female) were separately recruited for the CAI portion of the study through advertisements in the hospital and community. Participants were $\geq 7$ years of age (range, 7.83-18.00 years old; Fig. $1 B$ ) at the time of interview to ensure sufficient autobiographical memory ability (Wheeler et al., 1997; Willoughby et al., 2012). The CAI, standardized memory testing, and MRI scanning all occurred between 2013 and 2015. Healthy control participants had no history of traumatic brain injury, neurological condition, learning disability, or developmental delay. The PFT and control groups did not significantly differ in terms of age at assessment $\left(t_{(39)}=-0.752, p=0.456\right)$ or maternal education $\left(t_{(36)}=1.346, p=0.187\right)$. All participants spoke fluent English (Table 1). Parents provided written, informed consent, and participants also provided verbal consent before beginning the CAI. If participants felt uncomfortable at any time during the interview, the interview was terminated. One PFT participant was excluded from MRI analysis and behavioral data analysis due to early termination of the CAI. 
A

\begin{tabular}{|c|}
\hline $\begin{array}{l}\text { EVENT } \\
\text { "Okay, um, well, my first day of school on, when I was in SK, I was about } 5 \text { I think. And I }\end{array}$ \\
\hline $\begin{array}{cc}\text { EXTERNAL EVENT } & \text { THOUGHT } \\
\text { just moved to a new school and I was really nervous. And my mom had to leave me, so }\end{array}$ \\
\hline $\begin{array}{c}\text { PLACE } \\
\text { I had to walk into school by myself. And I remember the hockey nets and going into the }\end{array}$ \\
\hline $\begin{array}{l}\text { PERCEPTUAL PLACE } \\
\text { hall, and then I remember sitting down in the classroom with our teacher, and um, she }\end{array}$ \\
\hline $\begin{array}{c}\text { SEMANTIC EVENT } \\
\text { - well, it's a French immersion school - she said 'Bonjour', and stuff like that, and then }\end{array}$ \\
\hline $\begin{array}{l}\text { EVENT THOUGHT } \\
\text { we had to partner up. It was really weird because we had to partner up with someone }\end{array}$ \\
\hline $\begin{array}{l}\text { EVENT } \\
\text { to go to the bathroom, and, um, so this girl um, she asked me if I wanted to be her }\end{array}$ \\
\hline $\begin{array}{l}\text { EVENT } \\
\text { PLACE }\end{array}$ \\
\hline $\begin{array}{l}\text { EVENT } \\
\text { the garbage can. And I remember walking out of the bathroom in disgust" }\end{array}$ \\
\hline
\end{tabular}
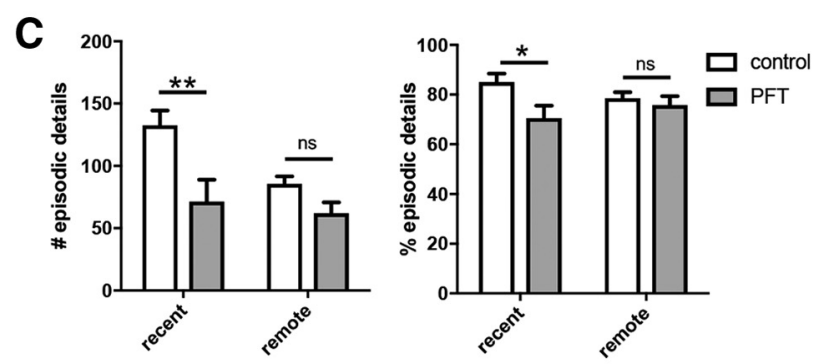

B
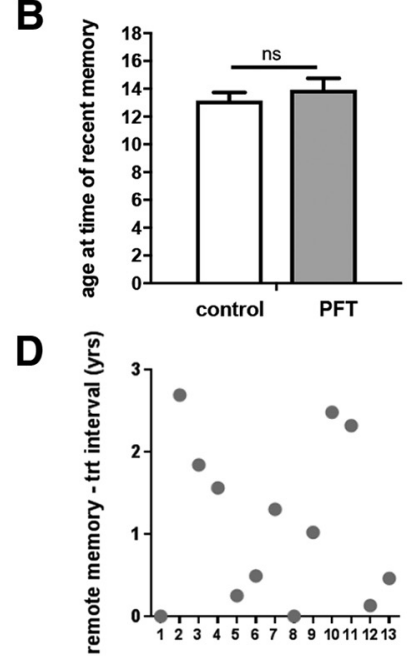

PFT patient
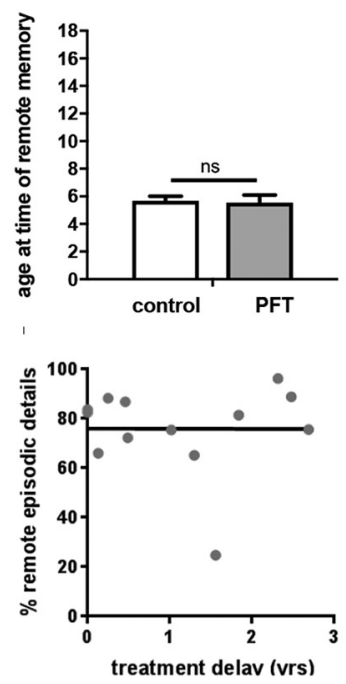

$\mathbf{F}$
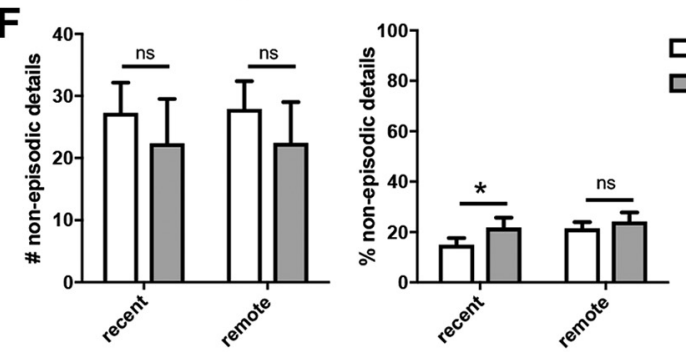

E
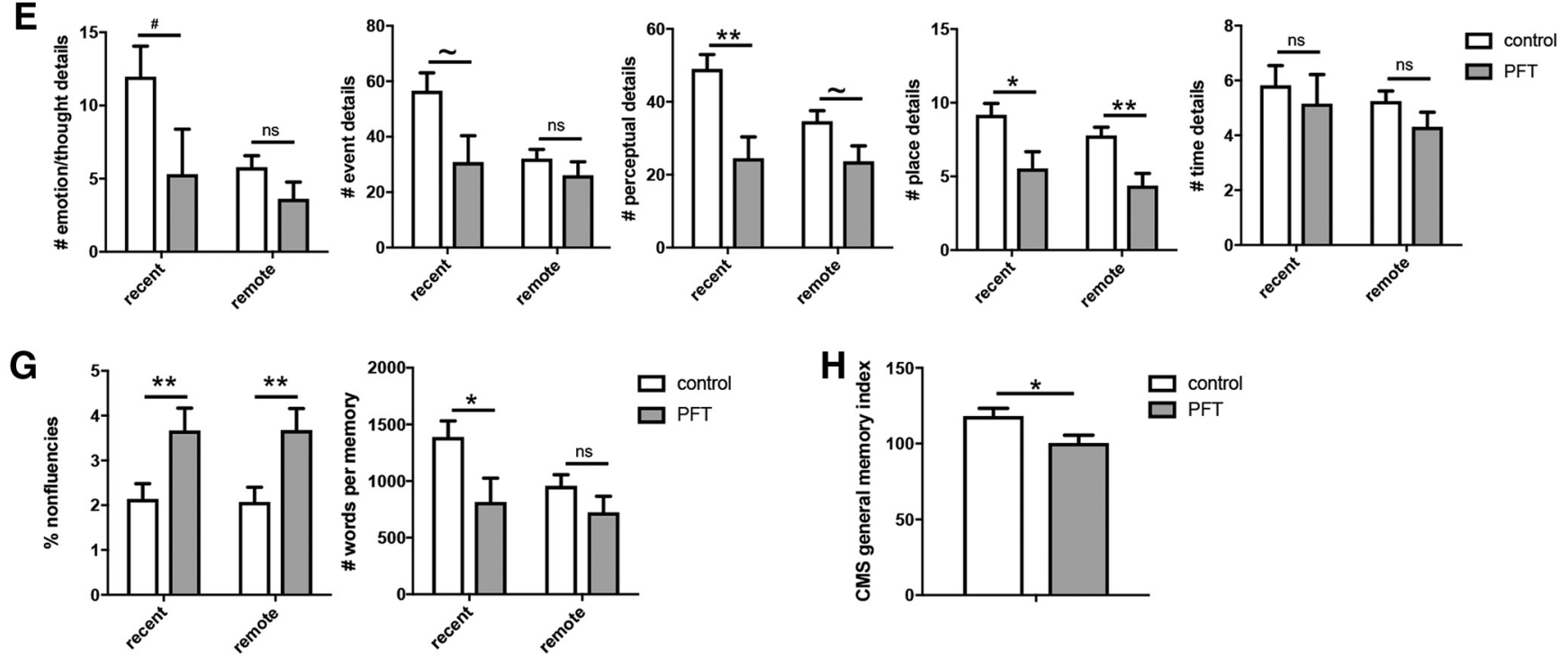

Figure 1. Autobiographical memory, general memory index, and verbal fluency deficits in PFT patients. $A$, Example of the scoring method used to code internal episodic (black: emotion/thought, event, perceptual, place, time) and nonepisodic (gray: semantic) details from a memory transcript. $\boldsymbol{B}$, Left, Mean age (years) at time of recent memory reported by controls (white) and PFT patients (gray) during the CAl. Right, Mean age (years) at time of remote memory reported by controls (white) and PFT patients (gray) during the CAl. C, Left, Total number of internal episodic details reported per memory narrative. Right, Percentage of internal episodic details reported per memory narrative. $\boldsymbol{D}$, Left, Interval between the age of initial treatment (trt) and the age at the time of the remote memory reported during the CAI for each PFT patient. Right, Plot of the percentage of episodic details recalled for remote memory and the delay between remote memory and radiotherapy treatment (years), including the best fitting linear regression line. $\boldsymbol{E}$, Number of each type of episodic detail (emotion/thought, event, perceptual, place, time) reported per memory narrative. $F$, Left, Total number of nonepisodic details (external details: semantic, repetitions, external unrelated events, and other metacognitive statements) reported per memory narrative. Right, Percentage of nonepisodic details reported per memory narrative. G, Left, Percentage of verbal nonfluencies per memory narrative. Right, Narrative fluency assessed by total word count per memory narrative for controls and PFT patients. $\boldsymbol{H}$, General memory index scores on the Children's Memory Scale (CMS) for controls (white) and PFT patients (gray). Error bars represent the SEM. ${ }^{*} p<0.01$, ${ }^{* *} p<0.001$, $\sim p<0.05$, \#p $=0.08$.

All procedures were approved by the Research Ethics Board at the Hospital for Sick Children and were conducted in accordance with the guidelines outlined by the Tri-Council Policy Statement: Ethical Conduct for Research Involving Humans.
CAI. The CAI was conducted individually in a sound-attenuated room by M.J.S. Participants were read a set of instructions and told that they would be asked to recall memories for a unique event (i.e., an event that occurred at a specific time and place) that they had personally experi- 
enced from two time points in their lives: (1) a remote memory from as long ago as they could remember (the remote event had to have occurred before radiation treatment for the PFT group); (2) a recent memory for an event occurring within the past month. The order of recent and remote memory testing was counterbalanced across participants. To assist participants in selecting an event, a list of typical events (e.g., a birthday party, graduation, getting a pet) was provided. Participants were told that they could select an event from the list, but that they were not restricted to the listed events.

Administration of the CAI was divided into three stages: free recall, general probe, and specific probe. During free recall, participants were allowed to talk about their memory of the event, uninterrupted by the experimenter, until their narrative had reached a natural end. The participant was then asked to give the event a name (e.g., "First day at a new school"). If the participant was unable to narrow down the memory to a unique event during the free-recall stage, they were allowed to select a new event. Next, during the general probe, the experimenter asked about key story elements reported during the free recall and prompted the participant to recall any additional details (e.g., "You mentioned your mom picking you up at the end of the day. Is there anything else you can tell me about that?"). Finally, during the specific probe, the experimenter asked a series of standardized questions (see Table 1-1, available at https://doi.org/10.1523/JNEUROSCI.1056-18.2018.t1-1) designed to elicit any additional details for their memory of the event (e.g., "Do you remember any tastes or smells from the event?"). The participant then rated their subjective feelings about the memory (e.g., how much emotional change did the event elicit, how personally important was the event, how clearly could they visualize the event, etc.) and the frequency of recalling the memory over time. Participants performed the free recall and general probe for each memory before performing the specific probe. This was done to prevent intentional inclusion of items from the specific probe list in the free-recall stage of the second memory. All interviews were audio recorded, then transcribed for scoring and narrative fluency analysis.

Scoring of the CAI. Interviews were scored by an experimenter (A.B.) with extensive training and experience scoring the $\mathrm{AI}$ and with previously demonstrated high inter-rater reliability (with intraclass correlation coefficients $>0.90$ for internal and external details). Transcripts were scored for internal (episodic) and external (nonepisodic) details. Internal, episodic details (subcategorized as event, time, place, perceptual/ sensory, thoughts/emotion details) are unique to the specific event, and relay a sense of reliving the experience (e.g., "the teacher said, 'Bonjour"'). External, nonepisodic details (subcategorized as semantic, repetitions, external unrelated events, and other metacognitive statements) contain information that are not unique to the specific event (e.g., "it was a French immersion school"). See Figure $1 A$ for an example of a scored narrative transcript. Scoring of all internal episodic and external nonepisodic details was collapsed across the three probing levels of the CAI to generate a single "episodic detail" score and a single "nonepisodic detail" score per participant.

Narrative fluency was also assessed using the Linguistic Inventory \& Word Count (LIWC) software (Pennebaker Conglomerates), which uses an integrated dictionary (LIWC2007; Pennebaker et al., 2007) to perform an automated word count as a measure of verbal fluency, and classifies the percentage of verbal nonfluencies (e.g., "umm," "er," "uh" in "umm, and we got down there, and er, uh.") in each reported memory.

Neuropsychological testing. A subset of participants also completed the CMS (for participants under 16 years; $n=8$ PFT, 8 controls; Cohen, 1997 ) or the Wechsler's Memory Scale (WMS-III; for participants between 16 and 18 years of age; $n=5$ PFT, 1 control; Wechsler, 1997). Using the CMS and WMS-III, a combined verbal and visual memory index score (general memory index) was calculated for each participant and used to corroborate memory performance on the CAI. Due to the limited number of controls who had completed the WMS-III, only data for the CMS are reported.

MRI data acquisition and preprocessing. T1-weighted structural MRI images were available for all 13 PFT patients and for 9 controls. Due to the limited number of control participants with structural MRI data, we included scans from a further 14 age-matched controls from the larger study who had not completed the CAI. MRI scans were performed at the Hospital for Sick Children on a Siemens 3 T TIM Trio scanner $(n=11$ PFT, 21 controls) using a 12-channel head coil. Due to the presence of metallic implants, a subset of patients $(n=2)$ were scanned on a General Electric 1.5 T Signa HDxt scanner. To minimize group differences in scan parameters, two of the 14 additional control participants selected were also scanned on a $1.5 \mathrm{~T}$ scanner.

Anatomical scans obtained with the $3 \mathrm{~T}$ scanner were acquired with a three-dimensional (3D) magnetization-prepared rapid acquisition with gradient echo sequence [repetition time $(\mathrm{TR})=2300 \mathrm{~ms}$; echo time $(\mathrm{TE})=3.91 \mathrm{~ms}$; inversion time $(\mathrm{TI})=900 \mathrm{~ms}$; voxel size, $1 \mathrm{~mm}$ isotropic; number of excitations, 1; pixel bandwidth, 240; 160 contiguous axial slices; FOV, $256 \times 224 \mathrm{~mm}$; flip angle, $\left.9^{\circ}\right]$. Anatomical scans obtained with the $1.5 \mathrm{~T}$ scanner were acquired with a $3 \mathrm{D}$ fast spoiled gradient echo inversion recovery prepared sequence $(\mathrm{TR}=10.056 \mathrm{~ms}$; $\mathrm{TE}=4.2 \mathrm{~ms}$; $\mathrm{TI}=400 \mathrm{~ms}$; voxel size, $0.9375 \times 0.9375 \mathrm{~mm}$; slice thickness, $1.5 \mathrm{~mm}$; number of excitations, 1 ; pixel bandwidth, 162.734 ; $116-124$ contiguous axial slices; FOV, $256 \times 224 \mathrm{~mm}$; flip angle, $20^{\circ}$ ).

All T1-weighted dicom files were converted to Analyze 7.5 file format. The Brain Extraction Tool (RRID:SCR_002823; http://www.fmrib.ox. ac.uk/fsl/) from the FSL [Oxford Centre for Functional MRI of the Brain (FMRIB) Software Library] was used to generate on each MR image a preliminary outline that separated the brain from nonbrain tissue (i.e., skull and CSF; Smith, 2002). This outline was manually corrected, slice by slice, in the axial plane and was used to obtain for each participant estimates of intracranial volume (ICV), which were controlled for in subsequent statistical analyses.

In preparation for segmenting the hippocampus, T1-weighted MR data of brains within skulls were converted to MINC (Medical Imaging NetCDF) file format. Hippocampal labeling was performed using the Multiple Automatically Generated Templates Brain Segmentation Algorithm (MAGeTbrain), a multiatlas-based segmentation tool (Chakravarty et al., 2013; Pipitone et al., 2014). This algorithm begins with a set of high-resolution manually labeled atlases as inputs. For this study, we used atlases that included definitions of the hippocampal subfields (Winterburn et al., 2013) and hippocampal white matter (Amaral et al., 2018). Specifically, this included labels of the CA1, CA2/3, CA4/dentate gyrus, subiculum, stratum radiatum/lacunosum/moleculare, and the fornix. To segment our dataset, these atlas labels were propagated through pairwise nonlinear registration to a subset of MR images in our dataset. Once labeled, this subset of images, referred to as the "template set," were nonlinearly registered to the entire set of MR images through pairwise matching. The most commonly occurring label at each voxel on each image was retained to generate the final segmentations. This algorithm has previously been validated for hippocampal segmentation and compares well with manual and automated segmentation techniques (Pipitone et al., 2014).

After subfields had been labeled, volumetric data were extracted for each hippocampal subfield and for the fornix in each hemisphere. Before analysis, raw volumes were adjusted for individual differences in ICV (Arndt et al., 1991; Free et al., 1995), according to previously described procedures (Riggs et al., 2014; Decker et al., 2017). Specifically, a regression coefficient between the sample mean ICV and each hippocampal subfield volume was calculated and used to adjust subfield volumes for each participant. Following adjustment for ICV, separate subfield volumes were manually inspected. For all analyses of hippocampal volume, hippocampal subfield volumes were summed to calculate bilateral and total hippocampal volumes.

Based on the hypothesis that autobiographical memory deficits in PFT patients would be associated with impairments in memory-processing regions, we additionally assessed cortical volume across five regions of the recollection network: the medial prefrontal cortex (mPFC), precuneus, posterior cingulate cortex (pCC), angular gyrus (AG), and lateral temporal cortex (LTC; Svoboda et al., 2006; Rugg and Vilberg, 2013). Cortical volume measurements were generated using the semiautomated cortical parcellation and volumetric segmentation Freesurfer pipeline (RRID:SCR_001847; http://surfer.nmr.mgh.harvard.edu; Fischl et al., 2002; Fischl, 2012). Structural volumes from the recollection network were adjusted for ICV using the aforementioned procedure. 
Experimental design and statistical analysis. All statistical analyses were conducted using SPSS 23 (RRID:SCR_002865; http://www-01.ibm.com/ software/uk/analytics/spss). Univariate ANOVAs were used to compare $\mathrm{ICV}$, hippocampus, and fornix volumes, and CMS performance. Repeated-measures ANOVA were used to assess performance on the CAI and LIWC. Multivariate ANOVA was used to assess group differences in cortical volume across five regions of the recollection network. One control participant was excluded due to technical difficulties with the Freesurfer analysis. Independent sample $t$ tests (two-tailed) were used to assess age at the time of recent memory, age at time of remote memory, and maternal education between groups, and to further assess significant ANOVA interactions between groups. Effects were considered significant at $p<0.05$. Bonferroni corrections for multiple comparisons were applied to post hoc $t$ tests. Bonferroni-corrected Pearson's correlations were performed for brain volume and behavioral measures of episodic details reported in the $\mathrm{CAI}$, and for correlations between remote memory age and the details reported in the CAI.

\section{Results}

\section{CAI results}

Age at time of memory

PFT patients and control participants were age-matched and therefore the age of the recent memory retrieval was also agematched between groups $\left(t_{(39)}=-0.752 p=0.456\right)$. The age at the time of the remote memory was also equivalent in both PFT patients and controls $\left(t_{(39)}=0.227 p=0.821\right)$. In patients, the average time lag between the remote memory recalled and treatment was $1.12( \pm 0.273)$ years (Fig. 1B).

\section{CAI episodic details}

To assess differences in the episodic quality of recent and remote memories, a repeated-measures ANOVA was conducted for the total number of episodic details (total internal details: thoughts/emotion, event, perceptual/sensory, place, time) per memory narrative, with time (recent, remote) as a within-subject factor, and group (PFT, control) as a between-subject factor. ANOVA revealed a main effect of time $\left(F_{(1,39)}=11.329, p=0.002, \eta^{2}=0.225\right)$, a main effect of group $\left(F_{(1,39)}=8.575, p=0.006, \eta^{2}=0.180\right)$, and a significant time $\times$ group interaction $\left(F_{(1,39)}=5.070, p=0.030, \eta^{2}=0.155\right)$. This interaction supports the conclusion that the episodic component of autobiographical memories is especially poor in PFT patients (compared with controls) at the recent, but not remote, time point. Indeed, post hoc tests confirmed that autobiographical memories in PFT patients contained fewer details at the recent time point only $\left(t_{(39)}=2.892, p=0.006\right.$; Fig. $\left.1 C\right)$. Paired-sample $t$ tests reveal that PFT patients report similar numbers of episodic details for recent and remote memories $\left(t_{(12)}=0.667, p=0.517\right)$, whereas controls report significantly more episodic details during retrieval of their recent, relative to remote, memories $\left(t_{(27)}=5.012, p<0.001\right)$.

PFT patients reported shorter memories relative to controls (see below; Fig. 1G). To control for this, we next examined the proportion of episodic and nonepisodic details in PFT patients versus controls. When a similar ANOVA was conducted for the percentage of episodic details, no significant main effect of time $\left(F_{(1,39)}=0.62, p=0.804, \eta^{2}=0.002\right)$ or group $\left(F_{(1,39)}=3.610\right.$, $\left.p=0.065, \eta^{2}=0.085\right)$ was found, but a significant time $\times$ group interaction $\left(F_{(1,39)}=4.908, p=0.033, \eta^{2}=0.112\right)$ was confirmed. These results highlight the impoverished episodic detail reported during recent memory by PFT patients $\left(t_{(39)}=2.396\right.$, $p=0.021)$, but the relative sparing of episodic remote memory relative to healthy controls $\left(t_{(39)}=0.628, p=0.534\right.$; Fig. $\left.1 C\right)$. As seen with the absolute number of reported episodic details, further analyses found that PFT patients report a similar proportion of episodic details for recent and remote memories $\left(t_{(12)}=\right.$ $-0.728, p=0.480)$, while controls report proportionally more episodic details of recent, relative to remote, memories $\left(t_{(27)}=\right.$ 4.2992, $p<0.001)$.

We next assessed whether the time of radiotherapy treatment might have affected internal detail production - that is, whether the shorter the lag time between the remote memory and treatment would result in the retention of more episodic details. However, likely due to the underpowered sample, no clear pattern was evident in the relationship between the treatment-remote memory lag and the percentage of episodic details reported for the remote memory $(r=-0.004, p=0.990$; Fig. $1 D)$.

To determine whether a particular type of internal detail was driving the above differences observed between groups, we next performed a repeated-measures ANOVA for the total number of each type of internal episodic detail (thoughts/emotion, event, perceptual, place, time) per memory narrative, with time and group. ANOVA revealed a main effect of detail type $\left(F_{(1,39)}=\right.$ 36.148, $\left.p<0.001, \eta^{2}=0.481\right)$ and confirmed main effects of time $\left(F_{(1,39)}=11.329, p=0.002, \eta^{2}=0.225\right)$ and $\operatorname{group}\left(F_{(1,39)}=\right.$ $\left.8.575, p=0.006, \eta^{2}=0.180\right)$, as well as a significant time $\times$ group interaction $\left(F_{(1,39)}=5.07, p=0.030, \eta^{2}=0.115\right)$. A significant detail type $\times$ time interaction emerged $\left(F_{(1,39)}=7.549, p=0.009\right.$, $\left.\eta^{2}=0.162\right)$. Also, we saw trends toward a detail type $\times$ group interaction $\left(F_{(1,39)}=3.224, p=0.080, \eta^{2}=0.076\right)$ and a detail type $\times$ time $\times$ group interaction $\left(F_{(1,39)}=4.041, p=0.051, \eta^{2}=\right.$ $0.094)$. Paired-sample $t$ tests revealed that, relative to recent memories reported by controls, PFT patients report significantly fewer perceptual/sensory $\left(t_{(39)}=3.481, p<0.001\right)$ and place $\left(t_{(39)}=2.637\right.$, $p=0.010)$ details, and a trend toward fewer event $\left(t_{(39)}=2.229, p=\right.$ $0.032)$ and emotion/thought $\left(t_{(39)}=1.786, p=0.082\right)$ details, but a comparable number of time details $\left(t_{(39)}=0.519, p=0.606\right)$. Relative to controls' remote memories, PFT patients report equivalent emotion/thought $\left(t_{(39)}=1.560, p=0.127\right)$, event $\left(t_{(39)}=1.020, p=\right.$ $0.314)$, and time $\left(t_{(39)}=1.451, p=0.155\right)$ details, but significantly fewer place details $\left(t_{(39)}=3.423, p=0.001\right)$, indicating a trend toward fewer perceptual details $\left(t_{(39)}=2.150, p=0.038\right)$ following Bonferroni correction for multiple comparisons (Fig. 1E). Together, these data suggest that, although PFT patients report fewer episodic details overall for their recent memories, memories of perceptual and place details are particularly sensitive to hippocampal dysfunction, regardless of the age of the memory.

\section{CAI nonepisodic details}

To assess differences in the nonepisodic quality of recent and remote memories, a repeated-measures ANOVA was conducted for the total number of external (nonepisodic) details (i.e., external event details, semantic details, repetitions, and other metacognitive thoughts) reported per memory narrative, with time as a within-subject factor, and group as a between-subject factor. No main effect of time $\left(F_{(1,39)}=0.026, p=0.872, \eta^{2}=0.001\right)$ or group $\left(F_{(1,39)}=0.421, p=0.520, \eta^{2}=0.011\right)$ and no time $\times$ group interaction $\left(F_{(1,39)}=0.016, p=0.899, \eta^{2}=0.001\right)$ were observed for the number of nonepisodic details. A similar ANOVA conducted for the proportion of nonepisodic details per memory revealed a significant main effect of time $\left(F_{(1,39)}=8.251\right.$, $\left.p=0.007, \eta^{2}=0.175\right)$, but no main effect of group $\left(F_{(1,39)}=\right.$ $\left.1.253, p=0.270, \eta^{2}=0.031\right)$ and no time $\times$ group interaction $\left(F_{(1,39)}=1.722, p=0.197, \eta^{2}=0.042\right)$. These findings highlight the time-dependent increase in the proportion of nonepisodic memory retrieved over time, but suggest that PFT patients' memory contains nonepisodic information comparable to that of controls (Fig. 1F). 

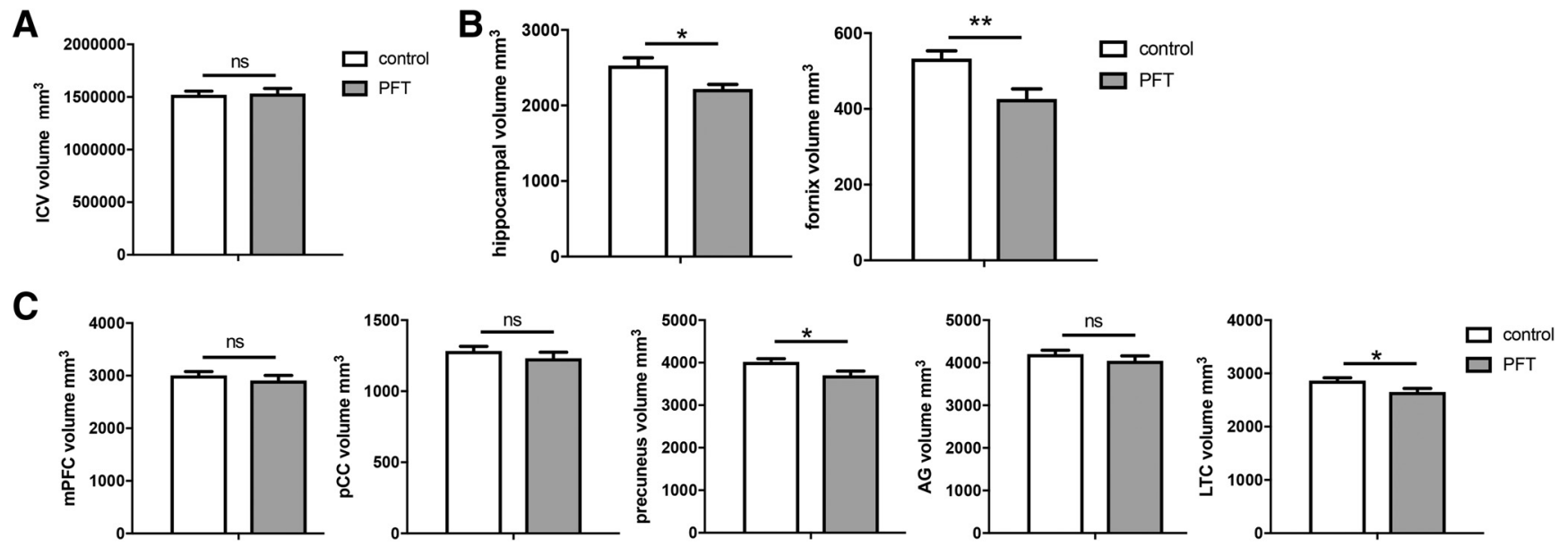

Figure 2. Brain volume deficits in PFT patients. $\boldsymbol{A}$, Mean ICV $\left(\mathrm{mm}^{3}\right)$ in controls (white) and PFT patients (gray). $\boldsymbol{B}$, Left, Mean volume (mm ${ }^{3}$ ) of the hippocampus in controls (white) and PFT patients (gray). Right, Mean volume $\left(\mathrm{mm}^{3}\right)$ of the fornix in controls (white) and PFT patients (gray). C, Mean cortical volume $\left(\mathrm{mm}^{3}\right)$ of the $\mathrm{mPFC}$, pCC, precuneus, AG, and LTC between controls (white bars) and PFT patients (gray bars). Error bars represent the SEM. ${ }^{*} p<0.05,{ }^{* *} p<0.01, \sim p=0.074$. ICV $=$ intracranial volume; $\mathrm{mPFC}=$ medial prefrontal cortex; $\mathrm{pCC}=$ posterior cingulate cortex; $\mathrm{AG}=$ angular gyrus; $\mathrm{LTC}=$ lateral temporal cortex.

\section{Narrative fluency}

In addition to gathering the novel findings related to autobiographical memory deficits emerging following radiotherapy treatment, we sought to replicate and extend previous investigations of cognitive deficits in PFT patients. Motivated by previous reports of speech and language impairment in PFT survivors (Huber et al., 2007; Lassaletta et al., 2015), we assessed verbal nonfluencies using the LIWC for recent and remote memories. A repeated-measures ANOVA conducted for the LIWC verbal nonfluencies with time as a within-subject factor and group as a between-subject factor revealed a significant main effect of group $\left(F_{(1,39)}=7.412, p=0.010, \eta^{2}=0.163\right)$, reflecting more verbal nonfluencies in PFT patients compared with controls. There was no significant main effect of time $\left(F_{(1,39)}=0.054, p=0.817, \eta^{2}=\right.$ $0.001)$ and no group $\times$ time interaction $\left(F_{(1,39)}=0.104, p=\right.$ $0.748, \eta^{2}=0.003$ ), indicating more nonverbal fluencies in PFT patients relative to controls regardless of whether a recent or remote memory was being recalled (Fig. $1 G$ ).

Excluding these nonfluencies from further analyses, we next assessed narrative fluency (i.e., word count per memory narrative) in PFT patients and controls. A repeated-measures ANOVA conducted for the LIWC word count per memory revealed a significant main effect of time $\left(F_{(1,39)}=11.138, p=0.002, \eta^{2}=\right.$ 0.222 ), reflecting reduced overall narrative fluency for more remote memories, a main effect of group $\left(F_{(1,39)}=4.151, p=\right.$ $\left.0.048, \eta^{2}=0.96\right)$, and a significant time $\times$ group interaction $\left(F_{(1,39)}=4.781, p=0.035, \eta^{2}=0.109\right)$, reflecting the fact that PFT patients reported shorter memories than controls at the recent memory time point $\left(t_{(39)}=2.299, p=0.027\right.$; Fig. $\left.1 G\right)$. Together, these findings of verbal dysfluency in PFT patients confirm previous reports of language impairments (Huber et al., 2007).

\section{Neuropsychological testing}

Finally, using the CMS, we assessed performance on a standardized battery of visual and verbal memory tasks designed to assess global memory function (Cohen, 1997; Monahan et al., 2001). A univariate ANOVA conducted with the CMS general memory index score as the dependent variable and group as the betweensubject factor revealed a significant main effect of group, with PFT patients scoring lower on the CMS general index than con- trols $\left(F_{(1,15)}=5.795, p=0.030, \eta^{2}=0.293\right.$; Fig. $\left.1 H\right)$. This replicates previous findings of memory-performance deficits on the CMS in PFT patients (Riggs et al., 2014) and supports the novel findings of impaired anterograde, but preserved retrograde, autobiographical memory in these patients.

\section{Brain volume results}

To test the prediction that episodic autobiographical memory deficits observed in PFT patients are mediated by disruptions to the medial-temporal lobe and related cortical regions in the recollection network following radiotherapy, we assessed hippocampal volume, white matter volume in the fornix, and cortical volume across the recollection network.

To control for differences in global brain volume, we first assessed potential differences in overall ICV (Fig. 2A). Univariate ANOVAs revealed no differences in ICV between PFT patients and healthy controls $\left(F_{(1,34)}=0.044, p=0.835, \eta^{2}=0.001\right)$. Following corrections for ICV, and consistent with previous reports (Riggs et al., 2014; Decker et al., 2017), hippocampal volume was reduced in PFT patients compared with controls $\left(F_{(1,34)}=4.632, p=0.039, \eta^{2}=0.120\right)$. A second ANOVA revealed reduced fornix volumes in PFT patients relative to controls $\left(F_{(1,34)}=10.672, p=0.002, \eta^{2}=0.239\right.$; Fig. $\left.2 B\right)$. We additionally assessed whether medial temporal lobe volume reductions were consistent across hemispheres. When hemisphere was included in our ANOVAs as a within-subjects factor, we found no main effects of hemisphere, nor hemisphere $x$ group interactions (all $p$ 's $>0.05$ ), but confirmed a main effect of group $\left(F_{(1,34)}=4.632, p=0.039, \eta^{2}=0.120\right)$, suggesting that radiotherapy treatment bilaterally affected medial temporal lobe structures.

Given the selective memory deficits observed in PFT patients, we also assessed cortical volume across brain regions previously associated with recollection (i.e., the putative recollection network). Relative to controls, PFT patients had reduced volume in the precuneus $\left(F_{(1,33)}=6.360, p=0.017, \eta^{2}=0.162\right)$ and LTC $\left(F_{(1,33)}=6.442, p=0.016, \eta^{2}=0.163\right)$. No group differences were observed in volume of $\operatorname{mPFC}\left(F_{(1,33)}=0.648, p=0.427\right.$, $\left.\eta^{2}=0.019\right), \operatorname{pCC}\left(F_{(1,33)}=0.895, p=0.351, \eta^{2}=0.026\right)$, or the $\operatorname{AG}\left(F_{(1,33)}=1.230, p=0.275, \eta^{2}=0.036\right.$; Fig. $\left.2 C\right)$. 


\section{A}
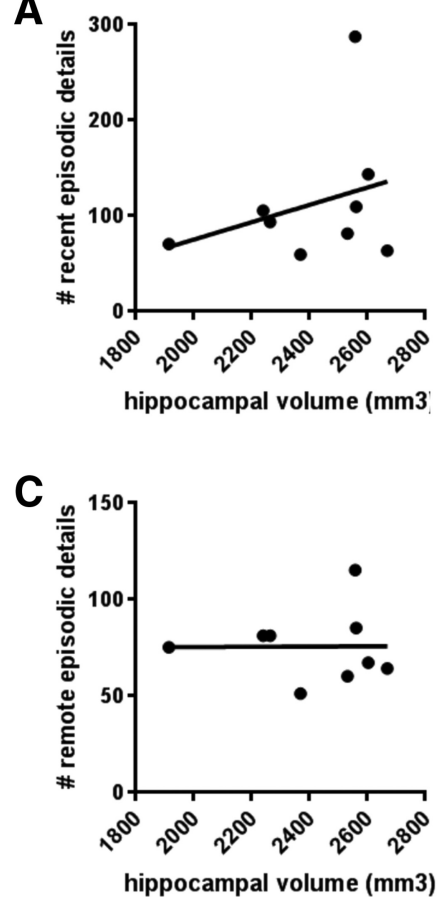
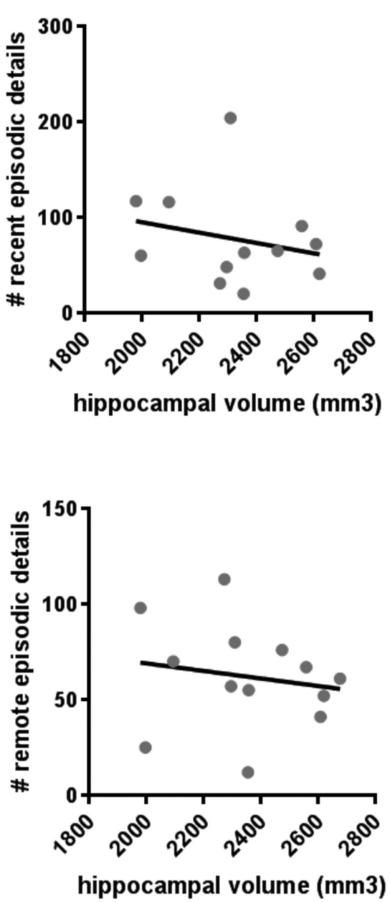

B
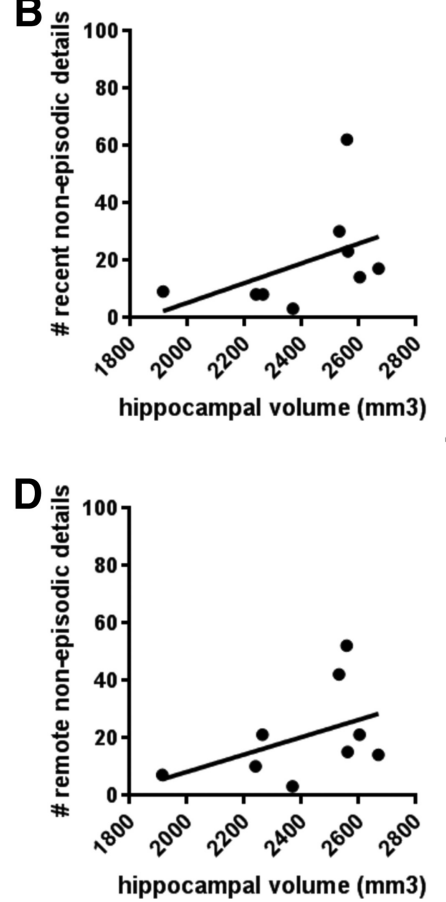
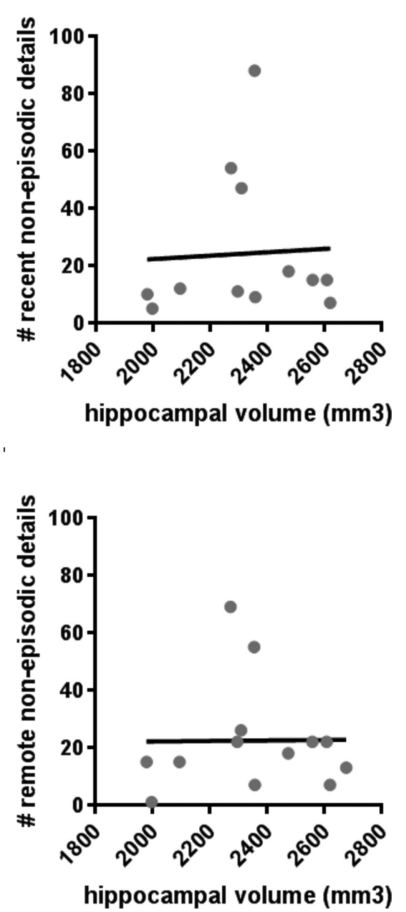

Figure 3. Relationship between hippocampal volume and the number of reported episodic and nonepisodic details. $\boldsymbol{A}$, Plot of the number of recent episodic details recalled and hippocampal volume for controls (left, black circles) and PFT patients (right, gray circles). B, Plot of the number of recent nonepisodic details recalled and hippocampal volume for controls (left, black circles) and PFT patients (right, gray circles). C, Plot of the number of remote episodic details recalled and hippocampal volume for controls (left, black circles) and PFT patients (right, gray circles). $\boldsymbol{D}$, Plot of the number of remote nonepisodic details recalled and hippocampal volume for controls (left, black circles) and PFT patients (right, gray circles). For each plot, the mean number of details recalled is reported on the $y$-axis and the mean hippocampal volume $\left(\mathrm{mm}^{3}\right)$ is reported on the $x$-axis. Each plot includes the best fitting linear regression line.

Finally, we assessed the potential correlation between hippocampal volume and the number of episodic details reported for recent and remote memories. As above, the power of this analysis was even further limited by the small sample of participants who completed both the CAI and structural MRI scans. No significant correlations were evident between hippocampal volume and the number of episodic details from recent memory in PFT patients $(r=-0.368, p=0.216)$ or controls $(r=0.309, p=$ 0.419 ; Fig. $3 A$ ), nor were there significant correlations between hippocampal volume and the number of episodic details from remote memory in PFT patients $(r=-0.167, p=0.586)$ or controls $(r=0.008, p=0.983$; Fig. $3 C)$. Additionally, no significant correlations were evident between hippocampal volume and the number of nonepisodic details from recent memory in PFT patients $(r=0.067, p=0.828)$ or controls $(r=0.458, p=$ 0.215 ; Fig. $3 B$ ), or between hippocampal volume and nonepisodic details for remote memory in PFT patients $(r=0.010, p=$ $0.973)$ or controls $(r=0.446, p=0.229$; Fig. $3 D)$. Similar correlational analyses conducted using the percentage of details reported for recent and remote memories revealed no significant relationship with total hippocampal volume and memory quality (all p's > 0.05).

Sex differences in cognitive performance and brain volume To determine whether males and females were differentially impaired following radiotherapy treatment, all analyses were performed using sex (male, female) and treatment as betweensubject variables of interest. We assessed sex differences in CMS performance using a univariate ANOVA. We assessed CAI performance (words per memory, verbal nonfluencies, detail analyses for recent and remote memories) and hippocampal volume using repeated-measures ANOVA. All analyses were performed using sex (male, female) and group as between-subject variables of interest. No significant main effect of sex and no interactions were found between sex and group or between sex and time for any measure (all $p$ 's $>0.05$; Fig. 4 ; detailed results not reported but available upon request). Given the relatively low incidence of PFT diagnosis in females relative to males, our sample size of female participants was low (four PFT patients), which may have limited the likelihood of detecting any significant effects of sex on the measures of interest. Future investigations into this patient population should seek to assess potential differences in memory susceptibility between male and female patients following cranial radiation.

\section{Discussion}

In this study we examined autobiographical memory in a patient population that had received radiotherapy for PFTs during childhood. Using the CAI, we retrospectively assessed memories from a period that either preceded or followed radiotherapy treatment. After treatment, recently experienced, episodic autobiographical memory was impaired in PFT patients relative to controls. In contrast, before treatment, remotely experienced, episodic autobiographical memories were equivalent in PFT patients and controls. This finding - that pretreatment episodic memories were preserved in patients receiving radiotherapy-is remarkable given that these patients had decreased hippocampal volume. It contrasts with the pattern that has been consistently observed in a range of conditions associated with hippocampal volume loss, including medial temporal lobe amnesia, mild cognitive impairment, Alzheimer's disease, temporal lobe epilepsy, transient epileptic amnesia, frontal temporal dementia, traumatic brain injury, encephalitis, and aging (Addis et al., 2007; Murphy et al., 2008; St-Laurent et al., 2009; Milton et al., 2010; Romero and Moscovitch, 2012; Irish et al., 2014; Dede et al., 2016; Esopenko and Levine, 2017; Miller et al., 2017). In 
A

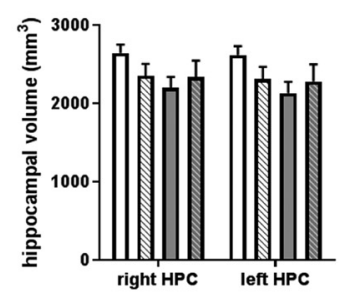

E

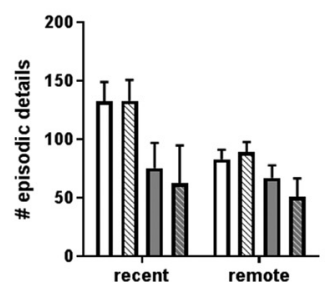

B

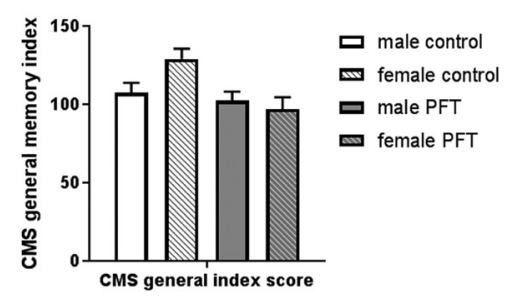

F

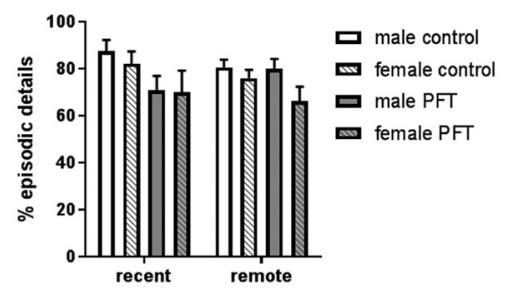

C

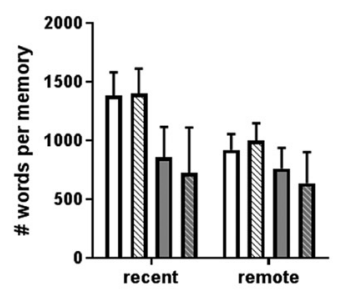

G

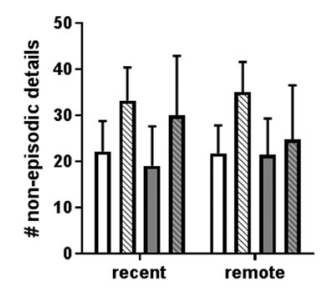

D

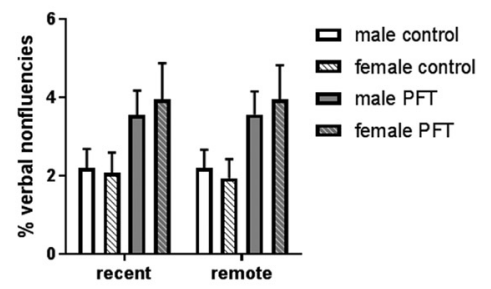

H

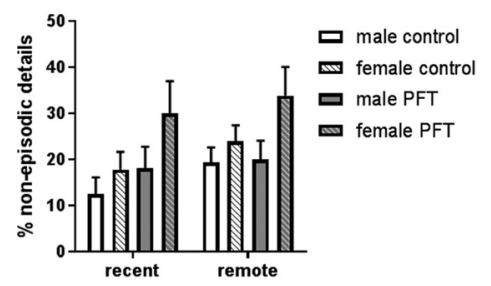

Figure 4. Hippocampal volume, autobiographical memory, general memory, and verbal fluency analyses by sex. $A$, Mean volume ( $\mathrm{mm}^{3}$ ) of the left and right hippocampus in male and female controls (males, white; females, white hatched) and PFT patients (males, gray; females, gray hatched). B, General memory index scores on the CMS for male and female controls and PFT patients. C, Verbal fluency assessed by total word count per memory narrative for male and female controls and PFT patients. D, Percentage of verbal nonfluencies per memory narrative for male and female controls and PFT patients. $E$, Total number of episodic details (internal details: event, time, place, perceptual/sensory, thoughts/emotion) reported per memory narrative for male and female controls and PFT patients. $\boldsymbol{F}$, Percentage of episodic details reported per memory narrative for male and female controls and PFT patients. $\mathbf{G}$, Total number of nonepisodic details (external details: semantic, repetitions, external unrelated events, and other metacognitive statements) reported per memory narrative for male and female controls and PFT patients. $\boldsymbol{H}$, Percentage of nonepisodic details reported per memory narrative for male and female controls and PFT patients.

these conditions, loss of episodic details (even in remote memories) accompanies hippocampal volume loss.

One way in which radiotherapy treatment might impair memory function is by reducing hippocampal neurogenesis. Indeed, postmortem immunohistochemical examination of brains from treated medulloblastoma patients has revealed a pronounced and persistent reduction in neurogenesis in the hippocampus (Monje et al., 2007). Staining for doublecortin (a marker of immature neurons) revealed a 10 -fold reduction in hippocampal neurogenesis that was evident $\leq 23$ years after treatment (Monje et al., 2007). Consistent with blunted hippocampal neurogenesis, PFT patients in the current study had reduced hippocampal volume, confirming observations in similar patient populations (Riggs et al., 2014; Decker et al., 2017).

In rodents, suppressing hippocampal neurogenesis similarly produces dissociable anterograde versus retrograde effects on memory (Frankland et al., 2013; Akers et al., 2014; Epp et al., 2016). In rodents, experimental suppression of hippocampal neurogenesis via cranial radiation (Raber et al., 2004; Winocur et al., 2006; Wojtowicz, 2006; Drew et al., 2010), pharmacological (Shors et al., 2001; Garthe et al., 2009; Martinez-Canabal et al., 2013), or genetic (Imayoshi et al., 2008; Deng et al., 2009) approaches produces anterograde memory deficits. For example, suppression of hippocampal neurogenesis impairs subsequent formation of spatial and contextual memories in mice and rats (Deng et al., 2010). In contrast, suppression of hippocampal neurogenesis may have protective effects on retrograde memory (i.e., on established hippocampal memories; Akers et al., 2014; Epp et al., 2016). In adult mice, post-training suppression of hippocampal neurogenesis attenuates natural forgetting of a spatial memory (Epp et al., 2016). In juvenile mice that rapidly forget, suppression of hippocampal neurogenesis slows this accelerated infantile forgetting (Akers et al., 2014). Since ongoing neurogenesis continuously remodels hippocampal circuits, it has been proposed that this remodeling "overwrites" memories stored in the hippocampus, potentially by modifying previously established synaptic connections within the hippocampus, thus rendering these memories less accessible (Frankland et al., 2013; Frankland and Josselyn, 2016; Richards and Frankland, 2017). Motivated by these rodent findings, we were interested in the current study in discovering whether anterograde and retrograde autobiographical memory would be differentially affected in PFT patients receiving radiotherapy. In line with the rodent studies outlined above, we made two predictions. First, we predicted that PFT patients would exhibit anterograde (i.e., post-treatment) memory impairments. Second, we predicted that, relative to control subjects, memory for pretreatment events would be superior in PFT patients.

Consistent with the first prediction, autobiographical memory for recently experienced (i.e., post-treatment) events was impaired in PFT patients. Compared with healthy controls, PFT patients reported fewer episodic details, suggesting deficits in their ability to either encode and/or retrieve highly detailed memories for personal events. The deficits in recollection of episodic information likely reflect impaired hippocampal function in these patients (i.e., reduced hippocampal volume and, possibly, reduced hippocampal neurogenesis). In contrast, PFT patients reported similar numbers of nonepisodic details compared with healthy controls, suggesting that neural systems supporting encoding and/or retrieval of semantic memory are relatively unaffected (or at least not sufficiently impaired to detect differences using the current methods to probe autobiographical memory). Similar disproportionate impairments in retrieval of episodic information have been previously reported in patients with hippocampal lesions. These patients display deficits in retrieval of episodic autobiographical memory details, but relative preservation of semantic memory (Viskontas et al., 2000; Addis et al., 2007; St-Laurent et al., 2009). It is important to note that medial temporal lobe damage beyond the hippocampus may also contribute to the observed deficits. For example, PFT patients additionally exhibited smaller volume of the 
fornix, consistent with previous reports of episodic autobiographical memory deficits associated with reduced integrity of the fornix (Hodgetts et al., 2017). This suggests that inefficient communication between the hippocampus and its downstream targets may also contribute to their observed deficits in episodic memory performance.

With respect to the second prediction, memories from the pretreatment period were generally unaffected in PFT patients. Despite reductions in hippocampal volume, there were no differences in the quality (episodic and nonepisodic details) or length of reported remote memories in PFT patients compared with healthy controls. Moreover, PFT patients reported a similar proportion of episodic details in their remote memories. Loss of episodic details, even in remote memories, consistently accompanies hippocampal volume loss across a wide range of conditions (Murphy et al., 2008; Rosenbaum et al., 2008; Race et al., 2011; St-Laurent et al., 2014). In this context, the preservation of detailed episodic memories from the pretreatment period in PFT patients is striking and provides partial (albeit incomplete) support for the idea that radiotherapy-induced suppression of hippocampal neurogenesis might protect these episodic memories from the pretreatment period. That is, radiotherapy, in reducing hippocampal neurogenesis, may serve to stabilize memories stored in those circuits while, at the same time, impairing the ability to form new (anterograde) episodic memories.

The sparing of remote memories in PFT patients may additionally reflect reduced hippocampal involvement in the recollection of these older autobiographical memories. As memories age, their retrieval becomes less dependent on the hippocampus and more dependent on cortical structures, including the mPFC (Gilboa et al., 2004; Bonnici et al., 2012; Bonnici and Maguire, 2018). The mPFC is located distally from the focal point of radiation surrounding the tumor bed. Consistent with this, we observed no differences in $\mathrm{mPFC}$ volume between PFT patients and healthy controls. Moreover, as memories age, they lose detail and become more gist-like, and their retrieval becomes less dependent upon the hippocampus (Moscovitch et al., 2016; Sekeres et al., 2017, 2018). Consistent with this, healthy controls reported fewer episodic details for their remotely, relative to recently, experienced events. These findings are in line with many previous studies that similarly report that episodic details of an event memory are especially susceptible to being forgotten over time, while the nonepisodic or more schematic elements of the memory are preferentially retained over time (Conway et al., 1991; Brainerd and Reyna, 2002; Sekeres et al., 2016). Yet internal remote details, although fewer, are still regarded as hippocampally mediated regardless of memory age, and these were preserved in PFT patients (Moscovitch et al., 2016). Indeed, one notable finding emerged when parsing the types of preserved internal details for recent and remote events. The finding that PFT patients are impaired in their retrieval of perceptual details and place details for both recent and remote memories fits with other studies that find this perceptually detailed information and spatial information relies on a functional hippocampus in perpetuity (Cohen and Eichenbaum, 1993; Lee et al., 2005; Moscovitch et al., 2016; Robin and Moscovitch, 2017).

However, our original prediction-that detailed episodic memories from the pretreatment period would be superior in PFT patients relative to controls-was not supported, as PFT patients did not report more episodic details from those remotely experienced, premorbid memories. One possible explanation that may account for these differences is based on the finding that, in PFT patients, radiotherapy causes damage beyond the hippocampus, and this extramedial temporal lobe damage likely counteracts the potentially protective effects of reduced hippocampal neurogenesis on premorbid memories. That is, treatment-related damage observed in other cortical regions within the memory-recollection network, including the precuneus and LTC, as well as broader deficits in white matter integrity that are commonly reported following cranial radiation (Riggs et al., 2014; Nieman et al., 2015; Decker et al., 2017), likely minimizes any savings in stability of premorbid memories as a consequence of blunted hippocampal neurogenesis.

In considering possible mechanisms, we have primarily focused our discussion on the effects of radiotherapy on hippocampal neurogenesis, given the strong links between radiotherapy and hippocampal neurogenesis and between hippocampal neurogenesis and memory function. However, we acknowledge that other treatment effects (associated with either anesthesia and chemotherapy), as well as mechanisms (e.g., effects on synaptogenesis, white matter, glia, vasculature, neuroinflammation, etc.), may additionally or alternatively contribute to the observed pattern of results.

Together, our findings provide insight into the complex cognitive impairments developing over extensive periods following conventional radiotherapy treatment for PFTs in children. Importantly, we confirmed findings of cognitive deficits in general memory, and of language impairments in PFT patients, but the current study identifies a previously uninvestigated domain of memory deficits and preservation following radiotherapy treatment. Assessing naturalistic autobiographical memory using the CAI identified specific deficits in the ability to form new episodic memories, while leaving pretreatment memories relatively intact despite significant hippocampal structural changes. The inability to easily form new memories pertaining to one's own personal experiences may diminish the quality of daily life for PFT survivors. Additionally, the relative preservation of retrograde memories points toward a sensitive time window for learning and retention of information before treatment. Together, these findings have significant implications for understanding complex, emerging deficits to the medial temporal lobe memory system and to the broader recollection network, which are inadvertently affected by standard treatment methods for PFTs in children.

\section{References}

Addis DR, Moscovitch M, Crawley AP, McAndrews MP (2004) Recollective qualities modulate hippocampal activation during autobiographical memory retrieval. Hippocampus 14:752-762. CrossRef Medline

Addis DR, Moscovitch M, McAndrews MP (2007) Consequences of hippocampal damage across the autobiographical memory network in left temporal lobe epilepsy. Brain 130:2327-2342. CrossRef Medline

Akers KG, Martinez-Canabal A, Restivo L, Yiu AP, De Cristofaro A, Hsiang HL, Wheeler AL, Guskjolen A, Niibori Y, Shoji H, Ohira K, Richards BA, Miyakawa T, Josselyn SA,Frankland PW (2014) Hippocampal neurogenesis regulates forgetting during adulthood and infancy. Science 344: 598-602. CrossRef Medline

Amaral RSC, Park MTM, Devenyi GA, Lynn V, Pipitone J, Winterburn J, Chavez S, Schira M, Lobaugh NJ, Voineskos AN, Pruessner JC, Chakravarty MM, Chakravarty MM (2018) Manual segmentation of the fornix, fimbria, and alveus on high-resolution 3T MRI: Application via fullyautomated mapping of the human memory circuit white and grey matter in healthy and pathological aging. Neuroimage 170:132-150. CrossRef Medline

Armstrong GT, Jain N, Liu W, Merchant TE, Stovall M, Srivastava DK, Gurney JG, Packer RJ, Robison LL, Krull KR (2010) Region-specific radiotherapy and neuropsychological outcomes in adult survivors of childhood CNS malignancies. Neuro Oncol 12:1173-1186. CrossRef Medline

Arndt S, Cohen G, Alliger RJ, Swayze VW 2nd, Andreasen NC (1991) Problems with ratio and proportion measures of imaged cerebral structures. Psychiatry Res 40:79-89. CrossRef Medline 
Bonnici HM, Maguire EA (2018) Two years later—revisiting autobiographical memory representations in vmPFC and hippocampus. Neuropsychologia 110:159-169. CrossRef Medline

Bonnici HM, Chadwick MJ, Lutti A, Hassabis D, Weiskopf N, Maguire EA (2012) Detecting representations of recent and remote autobiographical memories in vmPFC and hippocampus. J Neurosci 32:16982-16991. CrossRef Medline

Brainerd CJ, Reyna VF (2002) Fuzzy-trace theory and false memory. Curr Dir Psychol Sci 11:164-169. CrossRef

Chakravarty MM, Steadman P, van Eede MC, Calcott RD, Gu V, Shaw P, Raznahan A, Collins DL, Lerch JP (2013) Performing label-fusionbased segmentation using multiple automatically generated templates. Hum Brain Mapp 34:2635-2654. CrossRef Medline

Cohen NJ (1997) Examiner's manual: Children's Memory Scale. San Antonio, TX: Harcourt Brace and Company.

Cohen NJ, Eichenbaum H (1993) Memory, amnesia, and the hippocampal system. Cambridge, MA: MIT.

Conway MA, Cohen G, Stanhope N (1991) On the very long-term retention of knowledge acquired through formal education: twelve years of cognitive psychology. J Exp Psychol Gen 120:395-409. CrossRef

Copeland DR, deMoor C, Moore BD 3rd, Ater JL (1999) Neurocognitive development of children after a cerebellar tumor in infancy: a longitudinal study. J Clin Oncol 17:3476-3486. CrossRef Medline

Correa DD, DeAngelis LM, Shi W, Thaler H, Glass A, Abrey LE (2004) Cognitive functions in survivors of primary central nervous system lymphoma. Neurology 62:548-555. CrossRef Medline

Decker AL, Szulc KU, Bouffet E, Laughlin S, Chakravarty MM, Skocic J, de Medeiros CB, Mabbott DJ (2017) Smaller hippocampal subfield volumes predict verbal associative memory in pediatric brain tumor survivors. Hippocampus 27:1140-1154. CrossRef Medline

Dede AJ, Wixted JT, Hopkins RO, Squire LR (2016) Autobiographical memory, future imagining, and the medial temporal lobe. Proc Natl Acad Sci U S A 113:13474-13479. CrossRef Medline

Deng W, Saxe MD, Gallina IS, Gage FH (2009) Adult-born hippocampal dentate granule cells undergoing maturation modulate learning and memory in the brain. J Neurosci 29:13532-13542. CrossRef Medline

Deng W, Aimone JB, Gage FH (2010) New neurons and new memories: how does adult hippocampal neurogenesis affect learning and memory? Nat Rev Neurosci 11:339-350. CrossRef Medline

Drew MR, Denny CA, Hen R (2010) Arrest of adult hippocampal neurogenesis in mice impairs single - but not multiple - trial contextual fear conditioning. Behav Neurosci 124:446-454. CrossRef Medline

Ehrstedt C, Kristiansen I, Ahlsten G, Casar-Borota O, Dahl M, Libard S, Strömberg B (2016) Clinical characteristics and late effects in CNS tumours of childhood: do not forget long term follow-up of the low grade tumours. Eur J Paediatr Neurol 20:580-587. CrossRef Medline

Epp JR, Silva Mera R, Köhler S, Josselyn SA, Frankland PW (2016) Neurogenesis-mediated forgetting minimizes proactive interference. Nat Commun 7:10838. CrossRef Medline

Esopenko C, Levine B (2017) Autobiographical memory and structural brain changes in chronic phase TBI. Cortex 89:1-10. CrossRef Medline

Fischl B (2012) FreeSurfer. Neuroimage 62:774-781. CrossRef Medline

Fischl B, Salat DH, Busa E, Albert M, Dieterich M, Haselgrove C, van der Kouwe A, Killiany R, Kennedy D, Klaveness S, Montillo A, Makris N, Rosen B, Dale AM (2002) Whole brain segmentation: automated labeling of neuroanatomical structures in the human brain. Neuron 33:341355. CrossRef Medline

Frankland PW, Josselyn SA (2016) Hippocampal neurogenesis and memory clearance. Neuropsychopharmacology 41:382-383. CrossRef Medline

Frankland PW, Köhler S, Josselyn SA (2013) Hippocampal neurogenesis and forgetting. Trends Neurosci 36:497-503. CrossRef Medline

Free SL, Bergin PS, Fish DR, Cook MJ, Shorvon SD, Stevens JM (1995) Methods for normalization of hippocampal volumes measured with MR. Am J Neuroradiol 16:637-643. Medline

Garthe A, Behr J, Kempermann G (2009) Adult-generated hippocampal neurons allow the flexible use of spatially precise learning strategies. PloS One 4:e5464. CrossRef Medline

Gibson E, Monje M (2012) Effect of cancer therapy on neural stem cells: implications for cognitive function. Curr Opin Oncol 24:672-678. CrossRef Medline

Gilboa A, Winocur G, Grady CL, Hevenor SJ, Moscovitch M (2004) Re- membering our past: functional neuroanatomy of recollection of recent and very remote personal events. Cereb Cortex 14:1214-1225. CrossRef Medline

Hodgetts CJ, Postans M, Warne N, Varnava A, Lawrence AD, Graham KS (2017) Distinct contributions of the fornix and inferior longitudinal fasciculus to episodic and semantic autobiographical memory. Cortex 94:114. CrossRef Medline

Huber JF, Bradley K, Spiegler B, Dennis M (2007) Long-term neuromotor speech deficits in survivors of childhood posterior fossa tumors: effects of tumor type, radiation, age at diagnosis, and survival years. J Child Neurol 22:848-854. CrossRef Medline

Imayoshi I, Sakamoto M, Ohtsuka T, Takao K, Miyakawa T, Yamaguchi M, Mori K, Ikeda T, Itohara S, Kageyama R (2008) Roles of continuous neurogenesis in the structural and functional integrity of the adult forebrain. Nat Neurosci 11:1153-1161. CrossRef Medline

Irish M, Piguet O, Hodges JR, Hornberger M (2014) Common and unique gray matter correlates of episodic memory dysfunction in frontotemporal dementia and Alzheimer's disease. Hum Brain Mapp 35:1422-1435. CrossRef Medline

Kempermann G, Gage FH, Aigner L, Song H, Curtis MA, Thuret S, Kuhn HG, Jessberger S, Frankland PW, Cameron HA, Gould E, Hen R, Abrous DN, Toni N, Schinder AF, Zhao X, Lucassen PJ, Frisén J (2018) Human adult neurogenesis: evidence and remaining questions. Cell Stem Cell 23:2530. CrossRef Medline

Langer T, Martus P, Ottensmeier H, Hertzberg H, Beck JD, Meier W (2002) CNS late-effects after ALL therapy in childhood. Part III: neuropsychological performance in long-term survivors of childhood ALL: impairments of concentration, attention, and memory. Med Pediatr Oncol 38: 320-328. CrossRef Medline

Lassaletta A, Bouffet E, Mabbott D, Kulkarni AV (2015) Functional and neuropsychological late outcomes in posterior fossa tumors in children. Childs Nerv Syst 31:1877-1890. CrossRef Medline

Lee AC, Bussey TJ, Murray EA, Saksida LM, Epstein RA, Kapur N, Hodges JR, Graham KS (2005) Perceptual deficits in amnesia: challenging the medial temporal lobe 'mnemonic' view. Neuropsychologia 43:1-11. CrossRef Medline

Levine B, Svoboda E, Hay JF, Winocur G, Moscovitch M (2002) Aging and autobiographical memory: dissociating episodic from semantic retrieval. Psychol Aging 17:677-689. Medline

Mabbott DJ, Spiegler BJ, Greenberg ML, Rutka JT, Hyder DJ, Bouffet E (2005) Serial evaluation of academic and behavioral outcome after treatment with cranial radiation in childhood. J Clin Oncol 23:2256-2263. CrossRef Medline

Martinez-Canabal A, Akers KG, Josselyn SA, Frankland PW (2013) Agedependent effects of hippocampal neurogenesis suppression on spatial learning. Hippocampus 23:66-74. CrossRef Medline

Miller TD, Chong TT, Aimola Davies AM, Ng TWC, Johnson MR, Irani SR, Vincent A, Husain M, Jacob S, Maddison P, Kennard C, Gowland PA, Rosenthal CR (2017) Focal CA3 hippocampal subfield atrophy following LGI1 VGKC-complex antibody limbic encephalitis. Brain 140:12121219. CrossRef Medline

Milton F, Muhlert N, Pindus DM, Butler CR, Kapur N, Graham KS, Zeman AZ (2010) Remote memory deficits in transient epileptic amnesia. Brain 133:1368-1379. CrossRef Medline

Monahan MC, Fennell EB, Horton AM Jr (2001) Children's memory scale, by M. Cohen. San Antonio, TX: Psychological Corporation, 1997. Arch Clin Neuropsychol 16:193-198.

Monje ML, Vogel H, Masek M, Ligon KL, Fisher PG, Palmer TD (2007) Impaired human hippocampal neurogenesis after treatment for central nervous system malignancies. Ann Neurol 62:515-520. CrossRef Medline

Moscovitch M, Rosenbaum RS, Gilboa A, Addis DR, Westmacott R, Grady C, McAndrews MP, Levine B, Black S, Winocur G, Nadel L (2005) Functional neuroanatomy of remote episodic, semantic and spatial memory: a unified account based on multiple trace theory. J Anat 207:35-66. CrossRef Medline

Moscovitch M, Cabeza R, Winocur G, Nadel L (2016) Episodic memory and beyond: the hippocampus and neocortex in transformation. Annu Rev Psychol 67:105-134. CrossRef Medline

Murphy KJ, Troyer AK, Levine B, Moscovitch M (2008) Episodic, but not semantic, autobiographical memory is reduced in amnestic mild cognitive impairment. Neuropsychologia 46:3116-3123. CrossRef Medline

Nieman BJ, de Guzman AE, Gazdzinski LM, Lerch JP, Chakravarty MM, 
Pipitone J, Strother D, Fryer C, Bouffet E, Laughlin S, Laperriere N, Riggs L, Skocic J,Mabbott DJ (2015) White and gray matter abnormalities after cranial radiation in children and mice. Int J Radiat Oncol Biol Phys 93:882-891. CrossRef Medline

Northcott PA, Jones DT, Kool M, Robinson GW, Gilbertson RJ, Cho YJ, Pomeroy SL, Korshunov A, Lichter P, Taylor MD, Pfister SM (2012) Medulloblastomics: the end of the beginning. Nat Rev Cancer 12:818834. CrossRef Medline

Pennebaker JW, Chung CK, Ireland M, Gonzales A, Booth RJ (2007) The development and psychometric properties of LIWC2007. Austin, TX: Software Manual.

Pipitone J, Park MTM, Winterburn J, Lett TA, Lerch JP, Pruessner JC, Lepage M, Voineskos AN, Chakravarty MM, Chakravarty MM (2014) Multiatlas segmentation of the whole hippocampus and subfields using multiple automatically generated templates. Neuroimage 101:494-512. CrossRef Medline

Raber J, Rola R, LeFevour A, Morhardt D, Curley J, Mizumatsu S, VandenBerg SR, Fike JR (2004) Radiation-induced cognitive impairments are associated with changes in indicators of hippocampal neurogenesis. Radiat Res 162:39-47. Medline

Race E, Keane MM, Verfaellie M (2011) Medial temporal lobe damage causes deficits in episodic memory and episodic future thinking not attributable to deficits in narrative construction. J Neurosci 31:1026210269. CrossRef Medline

Ramaswamy V, Remke M, Adamski J, Bartels U, Tabori U, Wang X, Huang A, Hawkins C, Mabbott D, Laperriere N, Taylor MD, BouffetE (2016) Medulloblastoma subgroup-specific outcomes in irradiated children: who are the true high-risk patients? Neuro Oncol 18:291-297. CrossRef Medline

Reeves CB, Palmer SL, Reddick WE, Merchant TE, Buchanan GM, Gajjar A, Mulhern RK (2006) Attention and memory functioning among pediatric patients with medulloblastoma. J Pediatr Psychol 31:272-280. CrossRef Medline

Richards BA, Frankland PW (2017) The persistence and transience of memory. Neuron 94:1071-1084. CrossRef Medline

Riggs L, Bouffet E, Laughlin S, Laperriere N, Liu F, Skocic J, Scantlebury N, Wang F, Schoenhoff NJ, Strother D, Hukin J, Fryer C, McConnell D, Mabbott DJ (2014) Changes to memory structures in children treated for posterior fossa tumors. J Int Neuropsychol Soc 20:168-180. CrossRef Medline

Robin J, Moscovitch M (2017) Details, gist and schema: hippocampal-neocortical interactions underlying recent and remote episodic and spatial memory. Curr Opin Behav Sci 17:114-123. CrossRef

Roman DD, Sperduto PW (1995) Neuropsychological effects of cranial radiation: current knowledge and future directions. Int J Radiat Oncol Biol Phys 31:983-998. CrossRef Medline

Romero K, Moscovitch M (2012) Episodic memory and event construction in aging and amnesia. J Mem Language 67:270-284. CrossRef

Rosenbaum RS, Moscovitch M, Foster JK, Schnyer DM, Gao F, Kovacevic N, Verfaellie M, Black SE, Levine B (2008) Patterns of autobiographical memory loss in medial-temporal lobe amnesic patients. J Cogn Neurosci 20:1490-1506. CrossRef Medline

Rugg MD, Vilberg KL (2013) Brain networks underlying episodic memory retrieval. Curr Opin Neurobiol 23:255-260. CrossRef Medline

Scantlebury N, Bouffet E, Laughlin S, Strother D, McConnell D, Hukin J, Fryer C, Laperriere N, Montour-Proulx I, Keene D, Fleming A, Jabado N, Liu F, Riggs L,
Law N, Mabbott DJ (2016) White matter and information processing speed following treatment with cranial-spinal radiation for pediatric brain tumor. Neuropsychology 30:425-438. CrossRef Medline

Sekeres MJ, Bonasia K, St-Laurent M, Pishdadian S, Winocur G, Grady C, Moscovitch M (2016) Recovering and preventing loss of detailed memory: differential rates of forgetting for detail types in episodic memory. Learn Mem 23:72-82. CrossRef Medline

Sekeres, MJ, Moscovitch, M, Winocur, G (2017) Mechanisms of memory consolidation and transformation. In: Cognitive neuroscience of memory consolidation (Axmacher N, Rasch B, eds), pp 17-44. Heidelberg: Springer.

Sekeres MJ, Winocur G, Moscovitch M (2018) The hippocampus and related neocortical structures in memory transformation. Neurosci Lett 680:39-53. CrossRef Medline

Shors TJ, Miesegaes G, Beylin A, Zhao M, Rydel T, Gould E (2001) Neurogenesis in the adult is involved in the formation of trace memories. Nature 410:372-376. CrossRef Medline

Siffert J, Allen JC (2000) Late effects of therapy of thalamic and hypothalamic tumors in childhood: vascular, neurobehavioral and neoplastic. Pediatr Neurosurg 33:105-111. CrossRef Medline

Smith SM (2002) Fast robust automated brain extraction. Hum Brain Mapp 17:143-155. CrossRef Medline

Steinvorth S, Levine B, Corkin S (2005) Medial temporal lobe structures are needed to re-experience remote autobiographical memories: evidence from HM and WR. Neuropsychologia 43:479-496. CrossRef Medline

St-Laurent M, Moscovitch M, Levine B, McAndrews MP (2009) Determinants of autobiographical memory in patients with unilateral temporal lobe epilepsy or excisions. Neuropsychologia 47:2211-2221. CrossRef Medline

St-Laurent M, Moscovitch M, Jadd R, McAndrews MP (2014) The perceptual richness of complex memory episodes is compromised by medial temporal lobe damage. Hippocampus 24:560-576. CrossRef Medline

Svoboda E, McKinnon MC, Levine B (2006) The functional neuroanatomy of autobiographical memory: a meta-analysis. Neuropsychologia 44: 2189-2208. CrossRef Medline

Viskontas IV, McAndrews MP, Moscovitch M (2000) Remote episodic memory deficits in patients with unilateral temporal lobe epilepsy and excisions. J Neurosci 20:5853-5857. CrossRef Medline

Wechsler D (1997) Wechsler memory scale WMS-III, vol. 14. San Antonio, TX: Psychological Corporation.

Wheeler MA, Stuss DT, Tulving E (1997) Toward a theory of episodic memory: the frontal lobes and autonoetic consciousness. Psychol Bull 121: 331-354. Medline

Willoughby KA, Desrocher M, Levine B, Rovet JF (2012) Episodic and semantic autobiographical memory and everyday memory during late childhood and early adolescence. Front Psychol 3:53. CrossRef Medline

Winocur G, Wojtowicz JM, Sekeres M, Snyder JS, Wang S (2006) Inhibition of neurogenesis interferes with hippocampus-dependent memory function. Hippocampus 16:296-304. CrossRef Medline

Winterburn JL, Pruessner JC, Chavez S, Schira MM, Lobaugh NJ, Voineskos AN, Chakravarty MM (2013) A novel in vivo atlas of human hippocampal subfields using high-resolution $3 \mathrm{~T}$ magnetic resonance imaging. Neuroimage 74:254-265. CrossRef Medline

Wojtowicz JM (2006) Irradiation as an experimental tool in studies of adult neurogenesis. Hippocampus 16:261-266. CrossRef Medline 